\title{
Reação de cultivares de maracujazeiro em áreas com fusariose
}

\author{
Roseano Medeiros da Silva ${ }^{1,4}$, Márcia Michelle de Queiroz Ambrósio ${ }^{1}$, Ana Verônica Menezes de Aguiar ${ }^{1,4}$, Fábio \\ Gelape Faleiro $^{2}$, Acleide Maria Santos Cardoso ${ }^{3,5}$, Vander Mendonça ${ }^{1}$
}

${ }^{1}$ Programa de Pós-Graduação em Agronomia/Fitotecnia, Departamento de Ciências Vegetais, Universidade Federal Rural do Semi-Árido - UFERSA, Campus de Mossoró, RN, CEP: 59.625-900. ${ }^{2}$ Embrapa Cerrados, Planaltina, DF, CEP: 70770-901; ${ }^{3}$ Programa de Pós-Graduação em Agronomia/ Fitopatologia, Universidade Federal de Lavras - UFLA, Campus de Lavras, MG, CEP: 37.200-00. ${ }^{4}$ Bolsistas de Doutorado da Capes. ${ }^{5}$ Bolsista de Doutorado do CNPq.

Autor para correspondência: Roseano Medeiros da Silva (roseanomedeiros@gmail.com)

Data de chegada: 12/07/2016. Aceito para publicação em: 06/03/2017.

$10.1590 / 0100-5405 / 2217$

\section{RESUMO}

Silva, R. M.; Ambrósio, M.M.Q.; Aguiar, A.V.M.; Faleiro, F. G.; Cardoso, A.M.S.; Mendonça, V. Reaction of passion fruit cultivars in areas with fusariosis. Summa Phytopathologica, v.43, n.2, p.98-102, 2017.

O objetivo deste trabalho foi avaliar a sobrevivência de oito cultivares de P. edulis Sims. e a reação do maracujazeiro amarelo enxertado sobre Passiflora foetida L. em área com histórico de fusariose (Fusarium oxysporum f. sp. passiflorae) na região de Mossoró/RN. Foram conduzidos dois ensaios, onde foram plantadas oito cultivares de maracujazeiro (FB 200, FB 300, BRS Gigante Amarelo, BRS Sol do Cerrado, BRS Rubi do Cerrado, IAC 273, IAC 275 e IAC 277) e uma cultivar comercial 'redondo amarelo' da Topssed $^{\circledR}$ enxertada sobre $P$. foetida, em área naturalmente infestada com $F$. oxysporum $\mathrm{f}$. sp. passiflorae. O delineamento experimental adotado foi em blocos ao acaso, com quatro repetições e três plantas por parcela.
No ensaio I foi avaliado a sobrevivência das cultivares e no ensaio II, avaliou-se a incidência da fusariose e a classe de reação, identificando os tratamentos como resistentes, moderadamente susceptíveis e susceptíveis. Todas as cultivares (ensaio I) apresentaram baixos índices de sobrevivência aos 180 dias após o plantio. As cultivares não enxertadas (ensaio II) foram classificadas como susceptíveis, com incidência de fusariose variando de 22,22 a $91,67 \%$. Não houve registro de incidência de fusariose no maracujazeiro enxertado sobre $P$. foetida (ensaio II) durante o período de avaliação, mostrando-se como um porta-enxerto promissor para solos infestados com Fusarium oxysporum.

Palavras-chave: enxertia, genótipos, murcha, Passiflora edulis Sims.

\section{ABSTRACT}

Silva, R. M.; Ambrósio, M.M.Q.; Aguiar, A.V.M.; Faleiro, F. G.; Cardoso, A.M.S.; Mendonça, V. Reaction of passion fruit cultivars in areas with fusariosis. Summa Phytopathologica, v.43, n.2, p.98-102, 2017.

The aim of this study was to evaluate the survival of eight cultivars of $P$. edulis Sims. and the reaction of yellow passion fruit grafted on Passiflora foetida L. in an area with history of fusariosis (Fusarium oxysporum $\mathrm{f}$. sp. passiflorae) in the region of Mossoró/RN. Two assays were conducted, in which eight passion fruit cultivars (FB 200, FB 300, BRS Gigante Amarelo, BRS Sol do Cerrado, BRS Rubi do Cerrado, IAC 273, IAC 275 and IAC 277) were planted and a commercial cultivar 'yellow round' by Topssed ${ }^{\circledR}$ was grafted on $P$. foetida in an area naturally infested with $F$. oxysporum $\mathrm{f}$. sp. passiflorae. Experimental design was in randomized blocks with four replicates and three plants per plot. In Assay I the survival of cultivars was evaluated and in Assay II the incidence of fusariosis and the reaction class were evaluated, identifying treatments as resistant, moderately susceptible and susceptible. All cultivars (Assay I) showed low survival rates at 180 days after planting. Non-grafted cultivars (Assay II) were classified as susceptible, and fusariosis incidence ranged from 22.22 to $91.67 \%$. There was no record of fusariosis incidence in passion fruit grafted on $P$. foetida (Assay II) during the evaluation period, which showed to be a promising rootstock for soils infested with Fusarium oxysporum.

Keywords: Grafting, genotypes, Fusarium wilt, Passiflora edulis Sims.

O maracujazeiro amarelo (Passiflora edulis Sims) é uma frutífera que apresenta expressão econômica em ascensão no nordeste brasileiro. Atualmente o Brasil é o maior produtor mundial da fruta, com uma produção média total de 823 mil toneladas e uma produtividade em torno de 14,3 $\mathrm{t} \mathrm{ha}^{-1}$ em 2014 (1), porém a ocorrência de problemas fitossanitários tem contribuído nos últimos anos para a redução da vida útil e baixa produtividade dos plantios. Aguiar et al. (2) relatam que a fusariose é a principal causa de ocorrência de morte prematura, acarretando sérios danos econômicos, uma vez que reduz o tempo de exploração da cultura e até inviabiliza seu cultivo em algumas áreas, pois o patógeno causador desta doença apresenta estruturas de resistência (clamidósporos) que garante a sobrevivência do fungo no solo, por longos períodos.

A morte prematura das plantas, doença relacionada a fungos habitantes do solo, como Fusarium oxysporum f. sp. passiflorae, Fusarium solani f. sp. passiflorae (5), Phytophthora cinnamomi Rands e à bactéria Xanthomonas axonopodis pv. passiflorae (Pereira) Dye (6), demonstra-se como o principal problema da cultura, reduzindo a área plantada e limitando a produtividade. Essencialmente o F. oxysporum $\mathrm{f}$. sp. passiflorae provoca necrose no sistema vascular causando murcha da parte aérea, colapso e morte das plantas em qualquer estágio de desenvolvimento e o $F$. solani provoca podridão no colo e sistema 
radicular (13).

Por se tratar de uma doença vascular, o controle químico da fusariose não é eficiente. Neste caso, são empregadas medidas preventivas de controle cultural (7), além do uso de mudas enxertadas sobre porta-enxertos de espécies silvestres com potencial de resistência.

A propagação do maracujazeiro em escala comercial é realizada por via sexual, no entanto, a propagação assexuada (enxertia) poderá ter grande importância para a cultura na solução de problemas fitossanitários. A enxertia é uma técnica já estudada por vários pesquisadores para a propagação do maracujazeiro amarelo $(18,19$, 22) e se mostra como uma forma viável de produção de mudas.

Santos et al. (20) reportam que cada vez mais estão sendo realizadas hibridações interespecíficas com a espécie silvestre Passiflora foetida L. Esta espécie vem chamando a atenção de alguns pesquisadores para o estudo do melhoramento genético e utilização como porta-enxerto no controle da fusariose, porém não há na literatura resultados que comprovem esta resistência.

Entre as cultivares de maracujazeiros mais plantadas comercialmente, destacam-se as provenientes de seleção massal, que é realizada pelos próprios produtores ou empresas ligadas ao setor, e também, os híbridos obtidos por programas de melhoramento, como o caso dos híbridos intravarietais.

O objetivo deste trabalho foi avaliar a sobrevivência de oito cultivares de $P$. edulis Sims. e a reação do maracujazeiro amarelo enxertado sobre $P$. foetida em área com histórico de fusariose (Fusarium oxysporum f. sp. passiflorae) na região de Mossoró - RN.

\section{MATERIAL E MÉTODOS}

Foram conduzidos dois experimentos simultaneamente no período de fevereiro a novembro de 2012 em duas áreas experimentais pertencentes à Universidade Federal Rural do Semi-Árido (UFERSA), Mossoró - RN, Brasil. De acordo com a classificação climática de Köppen, o clima de Mossoró é do tipo BSwh', isto é, semiárido muito quente e com estação chuvosa no verão atrasando-se para o outono, apresentando temperatura média de $27,4^{\circ} \mathrm{C}$, com precipitação pluviométrica anual muito irregular e com umidade relativa média do ar de $68,9 \%$ (10). A observação das médias de temperaturas máximas e mínimas, umidade relativa do ar e precipitação para a época de condução do experimento foi interpretada com base no banco de dados meteorológicos do INMET (12) para a região de Mossoró, onde se observou que houve uma grande amplitude de variação durante o ano para temperatura $\left(24\right.$ a $30{ }^{\circ} \mathrm{C}$ ) e umidade relativa (52 a 94\%) sendo observados os maiores picos de temperaturas e umidade no primeiro semestre do ano, acompanhado de um acumulado de chuvas de pouco mais de $220 \mathrm{~mm}$ em 2012 na região.

O ensaio I foi instalado na fazenda Experimental Rafael Fernandes, distrito de Alagoinha, Mossoró - RN, onde foram plantadas oito cultivares de maracujazeiro e, o ensaio II instalado na área experimental do Departamento de Ciências Vegetais da UFERSA, com as oito cultivares e uma cultivar comercial enxertada sobre Passiflora foetida. Foram utilizadas sementes de oito cultivares de maracujazeiro, sendo duas obtidas dos viveiros Flora Brasil (FB 200 e FB 300), três híbridos produzidos pela Embrapa (BRS Gigante Amarelo, BRS Sol do Cerrado e BRS Rubi do Cerrado) e três cultivares do Instituto Agronômico de Campinas (IAC 273, IAC 275 e IAC 277) e uma cultivar (maracujazeiro amarelo da marca comercial Topssed ${ }^{\circledR}$ ) enxertada sobre a espécie $P$. foetida.

A semeadura foi realizada $(01 / 02 / 2012)$ em sacos de polietileno com capacidade para 0,7 litros, contendo substrato composto da mistura de arisco e esterco bovino curtido (3:1). Aos 30 dias após a semeadura foi realizado o processo de enxertia, pelo método de garfagem em fenda cheia, com amarrio da região enxertada com fita biodegradável e proteção com câmara úmida com saco plástico transparente (4 x 22 $\mathrm{cm})$, sem amarrio da base.

O plantio foi realizado aos 60 dias após a semeadura (02/04/2012), em dois locais com áreas já exploradas pela mesma cultura e com histórico de fusariose. As covas foram preparadas 30 dias antes, nas dimensões de 40 x 40 x $40 \mathrm{~cm}$ e colocado 10 litros de esterco bovino e uma mistura de $0,5 \mathrm{~kg}$ de uma formulação comercial de N-P-K (414-8). O sistema de condução foi em espaldeira de fio único, com 2 $\mathrm{m}$ de altura, espaçadas de 3,0 m entre plantas e 2,5 m entre fileiras, com uma população aproximada de 1.333 plantas ha ${ }^{-1}$. O sistema de irrigação adotado foi por gotejamento. Os tratos culturais e as adubações de cobertura foram realizados com base nas recomendações de Lima (15) para a cultura do maracujazeiro.

O delineamento experimental adotado foi em blocos ao acaso, com quatro repetições e três plantas por parcela, totalizando 12 plantas. Os tratamentos foram constituídos das oito cultivares e de uma cultivar enxertada. As avaliações de sobrevivência foram realizadas aos 60 dias após o plantio e, a cada 30 dias após a primeira avaliação até a observação de uma porcentagem superior a 75\% de mortalidade, devido ao severo ataque da doença na área onde foi conduzido o ensaio I.

No início da época de plena floração e frutificação, aos 6 meses após o plantio (23/10/12), foi realizado a avaliação de incidência da doença, identificando a porcentagem de plantas com sintomas de fusariose na área do ensaio II.

Todas as plantas que apresentavam sintomas foram coletadas, retirando-se amostras do tecido radicular que foram enviadas ao laboratório de Microbiologia e Fitopatologia da UFERSA para identificação do fungo causador da doença (14) e, posteriormente, para o laboratório de Fitopatologia da Universidade Federal de Lavras, UFLA, em Lavras-MG, para identificação das espécies de Fusarium obtidas das plantas com sintomas. Os isolados foram identificados como $F$. oxysporum f. sp. passiflorae.

A identificação dos isolados foi realizada com auxílio da chave dicotômica de identificação das espécies de Fusarium (4) e pela morfologia dos macroconídios e das características das monofiálides $(14,17)$, onde os autores descrevem que, isolados de $F$. oxysporum $\mathrm{f}$. sp. passiflorae apresentaram apenas fiálides curtas, com menos de 45 $\mu \mathrm{m}$ e com leve alargamento na base, assumindo o formato de "pino de boliche".

No ensaio I foi observado o número de plantas que permaneceram vivas até 180 dias e estimado em porcentagem de sobrevivência de plantas ao longo do tempo.

No ensaio II foi analisado a classe de reação com base na metodologia de Araújo et al. (3), identificando-se os tratamentos como resistente (tratamento que não apresentou planta morta), moderadamente susceptível (tratamento que apresentou pelo menos uma planta morta) e susceptível (tratamento com duas ou mais plantas mortas). A avaliação foi realizada aos 180 dias (6 meses) quando as plantas estavam em plena floração e frutificação.

Para fins de análise estatística foi representada a média de sobrevivência por tratamento, obtida pela média dos blocos, utilizandose a estatística descritiva para o processamento dos dados.

\section{RESULTADOS E DISCUSSÃO}

Com base na avaliação de sobrevivência das plantas no campo 


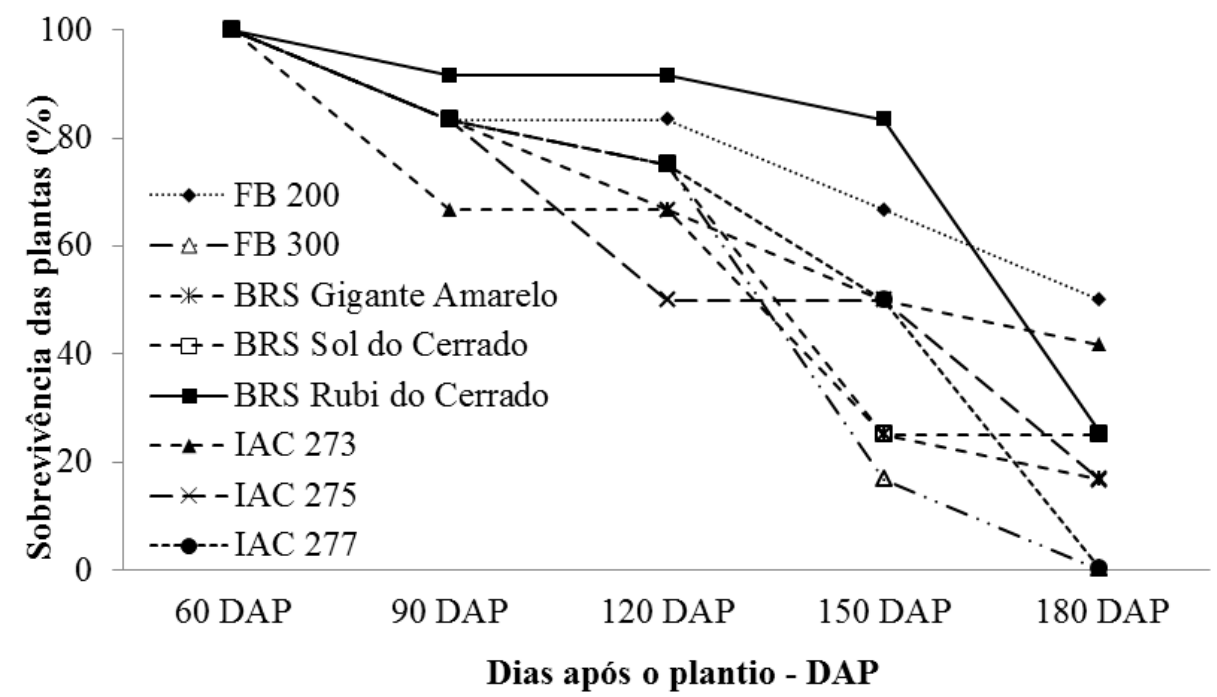

Figura 1. Médias de porcentagem de sobrevivência de plantas de oito cultivares de maracujazeiro (obtidas por mudas a partir de sementes) em área com histórico de fusariose em Mossoró - RN.

(Ensaio I), verifica-se que a partir dos 90 dias após o plantio, as cultivares começaram a apresentar taxa de mortalidade (Figura 1). Nesta mesma época, a maioria das plantas vivas estavam podadas na altura do arame $(2 \mathrm{~m})$.

Aos 150 dias após o plantio, havia grande quantidade de plantas em floração, portanto, também foi observado um pico maior na mortalidade das plantas. A cultivar BRS Rubi do Cerrado apresentou um comportamento de sobrevivência das plantas superior as demais, até os 150 dias de avaliação. Devido a grande massa vegetal produzida no desenvolvimento vegetativo da cultura, há a exigência de maior quantidade de água na irrigação para suprir a necessidade da planta. Isso pode estar relacionado ao fato do maior ataque da doença nesta fase de desenvolvimento da planta, associado ao aumento da umidade do solo que favorece o ataque, como relata Fischer \& Rezende (11). Quanto à morte precoce, Junqueira et al. (13), acreditam que a causa primária da doença seja o esgotamento repentino da planta em decorrência da alta produtividade e de um sistema radicular pouco eficaz na absorção de nutrientes. O estudo do desenvolvimento do sistema radicular em espécies de porta-enxerto deve ser levado em consideração, uma vez que este é uma estratégia que garante a sobrevivência das plantas.

Segundo Viana et al. (23), os sintomas da fusariose em plantas jovens e adultas se caracterizam pelo amarelecimento das folhas, podendo ou não ocorrer morte regressiva, evoluindo para queda das folhas basais, murcha e morte da planta, isso devido à interrupção dos vasos do xilema das raízes para os ramos.

Além das divergências na literatura quanto a descrição dos sintomas de fusariose, a doença ainda possui outras nomenclaturas, tais como podridão do colo e podridão do pé, murcha, ou ainda morte prematura, e têm sido associadas às espécies de Fusarium oxysporum f. sp. passiflorae e $F$. solani. Estes fungos habitantes do solo podem ser confundidos em função dos sintomas reflexos que causam nas plantas. Entretanto, F. solani está associado à podridão do colo, onde as plantas apresentam fendas na região do colo, e desenvolvimento de lesões deprimidas (9). Morfologicamente estas duas espécies se diferenciam principalmente pelas fiálides produzidas no micélio aéreo, sendo que F. oxysporum apresenta fiálides curtas e $F$. solani, fiálides longas.

Aos 180 dias após o plantio, mais de $78 \%$ da população de plantas, do ensaio I, já haviam morrido em decorrência do ataque da doença. As cultivares FB 200 e IAC 273 foram as que apresentaram maiores porcentagens de sobrevivência até os 180 dias, com 50 e 42\% respectivamente, já nas cultivares FB 300 e IAC 277 todas as plantas morreram (Figura 1). Araújo et al. (3), estudando a sobrevivência de cultivares de maracujazeiro em área infestada por Fusarium spp. observaram a mortalidade de todas as plantas das cultivares BRS Gigante Amarelo e FB 200 em pouco mais de um ano de cultivo, quando as mudas foram produzidas por semente.

As baixas taxas de sobrevivência alcançadas por todas as cultivares aos 180 dias após o plantio e, a tendência de redução destas taxas evidenciam que alternativas tecnológicas devem ser desenvolvidas para o cultivo do maracujazeiro nestas áreas com histórico de ocorrência de fusariose. As alternativas tecnológicas estão relacionadas ao manejo cultural e fitotécnico do pomar e ao uso de mudas enxertadas utilizando espécies silvestres de maracujazeiro resistentes à fusariose $(3,21)$.

O maior pico de mortalidade das plantas foi observado a partir dos 150 dias após o plantio, onde menos de $22 \%$ da população média das plantas permaneceram vivas até o final do experimento, evidenciando que alternativas tecnológicas devem ser desenvolvidas para a viabilidade econômica do cultivo do maracujazeiro, em áreas com histórico de fusariose.

Com relação aos resultados encontrados no ensaio II, observa-se que a maioria das cultivares não enxertadas apresentaram taxas de mortalidade superiores a 50\%, com exceção da BRS Sol do Cerrado $(22,22 \%)$ e FB $200(33,33 \%)$ que apresentaram as menores taxas. Não houve nenhum registro de mortalidade para a cultivar Redondo Amarelo enxertada sobre a espécie $P$. foetida até os 180 dias de avaliação (Tabela 1).

Muitas espécies silvestres já são utilizadas como porta-enxerto no controle de doenças do maracujazeiro, principalmente visando o controle da morte por fusariose. Estudos com a enxertia desta cultura visando o controle de patógenos habitantes do solo já são enfatizados por alguns autores $(2,8,13)$. Meletti (16) reforça que a enxertia do maracujazeiro amarelo sobre outras espécies não cultivadas, visando o controle da morte prematura de plantas ou da fusariose já é uma realidade em regiões afetadas por patógenos veiculados pelo solo. Porém, para a mesma autora, a aplicação do processo em escala comercial ainda tem-se mostrado antieconômica, devido à pequena disponibilidade das sementes das espécies de porta-enxerto, além da dificuldade e irregularidade de germinação da maioria. 
Tabela 1. Incidência de fusariose e classe de reação em cultivares de maracujazeiro em área com histórico da doença em Mossoró - RN, Brasil

\begin{tabular}{lll}
\hline Cultivares & $\begin{array}{l}\text { Incidência de } \\
\text { fusariose (\%) }\end{array}$ & Classe de reação ${ }^{2}$ \\
Enxertada (P. edulis/P. foetida) & 0,00 & Resistente \\
FB 200 & $33,33 \pm 0,82$ & Susceptível \\
FB 300 & $75,00 \pm 0,96$ & Susceptível \\
BRS Gigante Amarelo & $50,00 \pm 0,58$ & Susceptível \\
BRS Sol de Cerrado & $22,22 \pm 1,15$ & Susceptível \\
Rubi do Cerrado & $58,33 \pm 0,50$ & Susceptível \\
IAC 273 & $66,67 \pm 1,15$ & Susceptível \\
IAC 275 & $91,67 \pm 0,50$ & Susceptível \\
IAC 277 & $50,00 \pm 0,10$ & Susceptível \\
\hline Média & $49,69 \%$ & - \\
\hline
\end{tabular}

${ }^{1}$ Média da porcentagem de plantas com incidência de fusariose \pm desvio padrão da média; ${ }^{2}$ Classes de reação: Resistente (não apresentou plantas mortas), moderadamente susceptível (apresentou pelo menos uma planta morta) e susceptível (apresentou duas ou mais plantas mortas) (2).

De acordo com os resultados obtidos, observa-se que a espécie Passiflora foetida utilizada como porta-enxerto apresentou resistência, quando cultivada em solo com histórico de fusariose $(F$. oxysporum $\mathrm{f}$. sp. passiflorae) na régio de Mossoró (RN). Esses resultados promissores apontam para uma alternativa viável aos produtores da região, uma vez que a espécie é de fácil acesso, como também pode ser cultivada junto a uma área de produção, servindo de plantas matrizes para produção de sementes. A produção de sementes de plantas silvestres é muito importante quando se pretende trabalhar com a utilização da espécie, uma vez que, não há a necessidade da coleta na natureza, diminuído assim a agressão sobre a propagação natural da espécie.

Apesar dos resultados promissores para o uso do porta-enxerto de P. foetida em solo com fusariose, estes podem não ser suficientes para garantir a resistência do porta-enxerto a fusariose para outras regiões, uma vez que o comportamento pode ser influenciado por diversos fatores, entre eles, as condições ambientais. É necessário expor as plantas enxertadas com $P$. foetida a vários isolados de Fusarium, com níveis de virulência distintos, mistura de isolados e realizar o plantio em diferentes localidades com histórico de fusariose e com condições ambientais distintas, para se conhecer a estabilidade da resistência do material.

A cultivar BRS Rubi do Cerrado apresentou as maiores porcentagens de sobrevivência de plantas na maioria das épocas avaliadas. As cultivares FB 200 e IAC 273 foram as que apresentaram maiores porcentagem de sobrevivência aos 180 dias após o plantio na área do ensaio I, porém com índices abaixo de 50\%.

Não houve registro de incidência de fusariose no maracujazeiro enxertado sobre $P$. foetida (ensaio II) durante o período de avaliação, mostrando-se como um porta-enxerto promissor para solos com histórico dessa doença.

\section{AGRADECIMENTOS}

Ao CNPq e a Capes pelo apoio financeiro e concessão da bolsa de estudos. Ao corpo técnico do Laboratório de Sistemática e Ecologia de Fungos do Departamento de Fitopatologia da UFLA, pela identificação dos isolados de Fusarium.

\section{REFERÊNCIAS}

1. ABF. Anuário brasileiro da fruticultura. Santa Cruz do Sul: Editora Gazeta Santa Cruz, 2016. 88p.

2. Viana, F.M.P.; Freire, F.C.O.; Cardoso, J.E.; Vidal, J.C. Principais doenças do maracujazeiro na Região Nordeste e seu controle. Fortaleza: Embrapa Agroindústria Tropical, 2003. 12p. (Comunicado Técnico, 86).

3. Aguiar, A.V.M.; Silva, R.M.; Cardoso, E.A.; Maracajá, P.B.; Pires, H.G. Utilização de espécies de Passiflora spp. como porta-enxertos no controle de doenças do maracujazeiro. Agropecuária Científica no Semi-Árido, Patos, v.6, n.4, p.17-22, 2010.

4. Araujo, C.A.T.; Faleiro, F.G.; Semprebom, M.S.; Krause, W. Sobrevivência de plantas enxertadas de maracujazeiro em área com histórico de doenças causadas por Fusarium spp. no Mato Grosso. In: Congresso Brasileiro de Fruticultura, 21., 2012, Bento Gonçalves. Anais. Jaboticabal: Sociedade Brasileira de Fruticultura, 2012. p. 42018-4211.

5. Booth, C. Fusarium: laboratory guide to the identification of the major species. Kew: Common Wealth Mycological Institute, 1977. 58p.

6. Bueno, C.J.; Fischer, I.H.; Rosa, D.D.; Firmino, A.C.; Harakava, R.; OliO veira, C.M. G.; Furtado, E.L. Fusarium solani f. sp. passiflorae: a new forma specialis causing callor rot in yellow passion fruit. Plant Pathology, London, v.63, p.382-389, 2014.

7. Cavichioli, J.C.; Corrêa, L.S.; Boliani, A.C.; Oliveira, J.C. Uso de câmara úmida em enxertia hipocotiledonar de maracujazeiro-amarelo sobre três porta-enxertos. Revista Brasileira de Fruticultura, Jaboticabal, v.31, n.2, p.532-538, 2009.

8. Cavichioli, J.C.; Corrêa, L.S.; Garcia, M.J.M.; Fischer, I.H. Desenvolvimenm to, produtividade e sobrevivência de maracujazeiro-amarelo enxertado e cultivado em área com histórico de morte prematura de plantas. Revista Brasileira de Fruticultura, Jaboticabal, v.33, n.2, p.567-574, 2011.

9. Cavichioli, J.C.; Kasai, F.S.; Nasser, M.D. Produtividade e características físicas de frutos de Passiflora edulis enxertado sobre Passiflora giberti em diferentes espaçamentos de plantio. Revista Brasileira de Fruticultura, Jaboticabal, v.36, n.1, p.243-247, 2014.

10. Dariva, J.C.; Xavier, A.A.; Costa, M.R.; Ribeiro, R.C.F.; Sousa, T.V. Variaa bilidade genética de isolados de Fusarium solani e Fusarium oxysporum f. sp. passiflorae associados ao maracujazeiro. Revista Brasileira de Fruticultura, Jaboticabal, v.37, n.2, p.377-386, 2015.

11. Espínola Sobrinho, J.; Pereira, V.C.; Oliveira, A.D.; Santos, W.O.; Silva, N.K.C.; Maniçoba, R.M. Climatologia da precipitação no município de Mossoró - RN período: 1900-2010. In: Congresso Brasileiro de Agrometeorologia, 17., 2011, Guarapari. Anais. Guaraparí: SBA/UFV, 2011. 1 CD-ROM.

12. Ficher, I.H.; Rezende, J.A.M. Disease of passion flower (Passiflora spp.). Pest Technology, Kagawa, v.2, n.1, p.1-19, 2008.

13. Instituto Nacional de Meteorologia - INMET. Dados agroclimatológico: estações meteorológicas convencionais do INMET. Brasília, 2013. Disponível em: <http://www.inmet.gov.br/climatologia/bol_agro/mapas.php>. Acesso em: 21 ago. 2013.

14. Junqueira, N.T.V.; Braga, M.F.; Faleiro, F.G.; Peixoto, J.R.; Bernacci, L.C. Potencial de espécies silvestres de maracujazeiro como fonte de resistência a doenças. In: Faleiro, F.G.; Junqueira, N.T.V.; Braga, M.F. (Ed.). Maracujá: germoplasma e melhoramento genético. Planaltina: Embrapa Cerrados, 2005. v.1, cap.4, p.81-106.

15. Leslie, J.F.; BrettA.S. The Fusarium laboratory manual. Ames: Blackwell Pub., 2006. v.2, 387p.

16. Lima, A.A. Aspectos fitotécnicos: desafios da pesquisa. In: Faleiro, F.G.; Junqueira, N.T.; Braga, M.F. (Ed.). Maracujá: germoplasma e melhoramento genético. Planaltina: Embrapa Cerrados, 2005. v.1, cap.26, p.643-674.

17. Meletti, M. M. Avanços na cultura do maracujá no Brasil. Revista Brasileira de Fruticultura, Jaboticabal, v.31, p.83-91, 2011. Número especial.

18. Nelson, P.E.; Touson, T.A.; Marassas, W.F.O. Fusarium species, an illustrated manual for identification. University Park: Pennsylvania State University Press, 1983. 193p.

19. Nogueira Filho, G.C.; Roncatto, G.; Ruggieiro, C.; Oliveira, J.C.; Malheiros, E.B. Propagação vegetativa do maracujazeiro: conquista de novas adesões. In: Faleiro, F.G.; Junqueira, N.T.V.; Braga, M.F. (Ed.). Maracujá: germoplasma e melhoramento genético. Planaltina: Embrapa Cerrados, 2005. v.1, cap.14, p.341-356.

20. Roncatto, G.; Assis, G.M.L.; Oliveira, T.K.; Lessa, L.S. Vegetative features 
of combinations scion/rootstock in passion fruit plant. Revista Brasileira de Fruticultura, Jaboticabal, v.33, n.3, p.791-797, 2011.

21. Santos, E.A.; Souza, M.M.; Viana, A.P.; Almeida, A.A.F.; Freitas, J.C.O.; Lawinscky, P.R. Multivariate analysis of morphological characteristics of two species of passion flower with ornamental potential and of hybrids between them. Genetics and Molecular Research, Ribeirão Preto, v.10, n.4, p.2457-2471, 2011.

22. Semprebom, M.S.; Faleiro, F.G.; Araujo, C.A.T.; Prado, L.L.; Haddad, F.; Junqueira, N.T.V. Tecnologia de mudas enxertadas de maracujazeiro azedo para controle de doenças causadas por Fusarium spp. no Mato Grosso - a experiência da Coopernova. In: Congresso Brasileiro de Fruticultura, 21., 2012, Bento Gonçalves. Anais. Jaboticabal: Sociedade Brasileira de Fruticultura, 2012. p.5575-5778.

23. Silva, R.M.; Aguiar, A.V.M.; Cardoso, E.A.; Souza, J.O.; Oliveira, L.A.A. Enxertia interespecífica do maracujazeiro-amarelo sobre quatro porta-enxertos. Revista Verde de Agroecologia e Desenvolvimento Sustentável, Mossoró, v.6, n.2, p.119-124, 2011

24. Viana, F.M.P.; Freire, F.C.O.; Cardoso, J.E.; Vidal, J.C. Principais doenças do maracujazeiro na Região Nordeste e seu controle. Fortaleza: Embrapa Agroindústria Tropical, 2003. 12p. (Comunicado Técnico, 86). 